\title{
REAKTUALISASI IMPLEMENTASI SISTEM PENDIDIKAN INTEGRATIF DI SEKOLAH DALAM MENGANTISIPASI DEGRADASI MORAL
}

\author{
Abdul Rahim \\ Universitas PGRI Yogyakarta \\ abdul@upy.ac.id
}

\begin{abstract}
Abstrak
Reaktualisasi Implementasi Sistem Pendidikan Integratif di Sekolah dalam Mengantisipasi Degradasi Moral ini bertujuan untuk memaparkan strategi dalam mereaktualisasi pelaksanaan sistem pendidikan yang terintegratif di sekolah untuk mengantisipasi degradasi moral. Metode penelitian dengan pendekatan kualitatif. Metode pengumpulan data digunakan teknik literatur, wawancara dan observasi. Metode analisis data digunakan metode deduktif. Kesimpulan yang dapat diambil dari pembahasan masalah reaktualisasi implementasi sistem pendidikan di sekolah dalam mengantisipasi degradasi moral adalah perlunya penyegaran kembali pelaksanaan sistem pendidikan di sekolah dengan membangun komitmen bersama seluruh stakeholder pendidikan untuk melaksanakan berbagai strategi. Strategi yang dapat ditempuh antara lain (1) penguasan sistem dalam budaya sekolah, dengan membangun budaya sekolah yang terfokus pada peningkatan moral, pembuatan slogan yang mengacu pada peningkatan moral, mapun membuat banner; (2) penguatan penguatan ESQ, EQ dan Pembiasaan seperti pemberian waktu yang longgar untuk melaksanakan ibadah bersama membangun warung kejujuran, serta (3) perubahan indoktrinasi kepada pembelajaran tidak langsung, dengan berbagai strategi pembelajaran yang mengarah pada pembentukan nilai sikap yang dilandasi oleh moral reasioning.
\end{abstract}

Kata kunci: Reaktualisasi, Sistem Pendidikan, Degradasi Moral

\begin{abstract}
Reactualization of the Implementation of the Integrative Education System in Schools in Anticipating Moral Degradation is intended to explain the strategy in re-actualizing the implementation of an integrated education system in schools for moral degradation review. Qualitative research methods. Data collection methods using literary techniques, interviews and observations. The data analysis method uses the deductive method. The conclusion that can be drawn from the discussion of the problem of reactivating the implementation of the education system in schools in the agreement on moral degradation is the need to refresh the implementation of the education system in schools by building a commitment together with all education stakeholders to implement various strategies. Strategies that can replace include (1) a satisfaction system in school culture, by building a school culture that focuses on improving morale, making slogans that raise morale, and making banners; (2) strengthening the strengthening of ESQ, EQ and Habituation as well as providing the assistance needed to build worship together with honesty stalls, and (3) indoctrination changes for indirect learning, with learning strategies that are in accordance with motivations based on moral reationing.
\end{abstract}

Key Words : Reactualization, Educational Systems, Moral Degradation

\section{PENDAHULUAN}

Kondisi ideal tentang penerapan sistem pendidikan yang sarat dengan nilainilai moral tersebut ternyata tidak selamanya berhasil membuat semua siswa mempunyai nilai moral yang tangguh. Beberapa kasus pelanggaran moral yang dilakukan oleh siswa seperti pelecehan seksual, perkelahian pelajar, kasus pembunuhan oleh siswa sering terdengar di berbagai stasiun televisi di Indonesia. Asumsi awal masyarakat kemudian lebih memojokkan sistem pendidikan di Indonesia sebagai penyebab kegagalan peningkatan moralitas. Apabila ditinjau dari berbagai kajian kebijakan sistem pendidikan di Indonesia, konsep peningkatan moral telah dirancang dengan 
muatan karakter yang kuat dalam setiap mata pelajaran, namun hal tersebut belum mampu menepis pelangaran moral yang dilakukan oleh oknum siswa.

Thomas Lickkona menyatakan terdapat sepuluh tanda-tanda zaman yang harus diwaspadai karena jika hal itu terjadi maka bangsa tersebut mengalami degradasi yiatu (1) meningkatnya kekerasan di kalangna remaja; (2) penggunaan bahasa dan kata-kata yang memburuk; (3) pengaruh pergaulan yang kuat dalam kekerasan; (4) meningkatnya perilaku merusak diri, seperti penggunaan narkoba, alkohol dan seks bebas; (5) semakin kaburnya pedoman moral baik dan buruk, (6) menurunnya etos kerja; (7) semakin rendahnya rasa hormat kepada orang tua dan guru; (8) rendahnya rasa tanggungjawab individu dan warga negara; (9) membudayakan ketidakjujuran, serta (10) adanya rasa saling curiga dan kebencian di antara sesama (Masnur Muslich, 2011:36).

Berdasarkan kajian tanda-tanda degradasi moral tersebut, perlu dianalisis seberapa tingkat degradasi moral di Indonesia. Idealisme sistem pendidikan yang telah menjadi kebijakan pemerintah tidak akan mampu untuk mengangkat moralitas siswa apabila penerapan pada tataran operasional pada pembelajaran guru tidak sesuai dengan konsep kurikulum. Oleh karena itu perlu pemikiran untuk kembali mereaktualisasi implementasi sistem pendidikan secara terintegratif untuk menganatisipasi degradasi moral di Indonesia termasuk pendidikan karakter. Tujuan dari diterapkannya program Penguatan Pendidikan Karakter adalah untuk menumbuhkan nilai-nilai karakter pada siswa secara terstruktur, sistematis dan masif seperti karakter religius, jujur, patriotisme dan lain-lain (Nurgiansah, 2019).

\section{METODE PENELITIAN}

Jenis penelitian yang digunakan dalam peneltian ini adalah penelitian kualitatif. metode penelitian kualitatif sering disebut dengan metode penelitian naturalistik (Nurgiansah \& Widyastuti, 2020). Langkah-langkah penelitian ditempuh dengan mengumpulkan datadata yang relevan dengan penelitian kemudian dikaji, dipaparkan serta disimpulkan. Trianggulasi data digunakan sebagai validasi penelitian dengan membandingkan berbagai sumber pengumpulan data. Data diperoleh dari guru SMP Muhammadiyah 1 Yogyakarta.

Sumber data utama dalam penelitian ini ialah kata-kata, dan tindakan (Lexy J Leong, 2008: 157). Teknik pengumpulan data pada penelitian ini antara lain: (a) Pengamatan adalah observasi dengan tujuan tertentu. Prinsip dasar pengamatan meliputi perencanaan bersama, memfokuskan objek observasi, membangun kriteria, mendefinisikan keterampilan observasi dan balikan (Wardhani dan Kuswaya Wihardit, 2010: 25).

Pengamatan dilakukan dengan mencermati berbagai budaya sekolah yang ada di SMP Muhammadiyah 1 Yogyakarta. (b) Wawancara dilakukan dengan guru SMP. Wawancara digunakan untuk mengungkapkan data yang berkaitan dengan sikap, pendapat atau wawasan. Wawancara merupakn pertanyaanpertanyaan yang diajukan secara verbal kepada orang-orang yang dianggap dapat memberikan informasi atau penjelasan halhal yang dipandang perlu dan memiliki reverensi dengan permasalahan. The interview is a data collection with a path of question and answer that is conducted systematically (Nurgiansah, 2020). (c) Literatur merupakan strategi memperoleh data dengan meggunakan berbagai literatur yang relevan dengan penelitian. Kajian-kajian dari berbagai bacaan 
tersebut menjadikan dasar konseptual terhadap masalah yang akan dikaji.

\section{HASIL PENELITIAN DAN PEMBAHASAN Hasil Penelitian}

Berdasarkan pengamatan di beberapa lembaga pendidikan, budaya sekolah mempengaruhi pembentukan moralitas siswa. Sekolah-sekolah yang mempunyai banyak kebijakan yang mendukung pengembangan moral siswa akan dapat menciptakan siswa yang mempunyai nilai moral yang kuat. Moralitas dapat diciptakan dengan memberikan suasana budaya sekolah yang terciptanya moral seperti guru yang telah menunggu siswa di gerbang sekolah mengandung nilai-nilai moral seperti bersosialisasi dengan sesama, kerapian, menyapa, saling memperhatikan dan berbagai nilai moral lainnya.

Pendidikan karakter pada tingkat satuan pendidikan mengarah pada pembentukan budaya sekolah, yaitu nilainilai yang perilaku, tradisi, kebiasaan sehari-hari, serta simbol- simbol yang diperaktekan oleh semua warga sekolah, dan masyarakat sekitarnya. Budaya sekolah merupakan ciri khas, karakter atau watak, dan citra sekolah tersebut di masyarakat luas. Teaches students to learnern to analyze and think systematically and critically in response (Nurgiansah \& Al Muchtar, 2018).

Berdasarkan studi literatur dan dokumentasi penelitian didapatkan data bahwa kurikulum di Indonesia telah mendukung terciptanya pembentukan moralitas siswa. Hal ini terbukti dengan adanya muatan moral yang kuat dalam kurikulum 2013. Dalam kurikulum 2013 terdapat kompetensi inti yang harus diacu untuk proses pembentukan output pembelajaran siswa. Kompetensi inti yang mengandung empat ranah yang saling mengkait antara aspek kognitif, aspek religi, aspek afektif, aspek psikomotor.
Keempat aspek tersebut saling terintegrasi satu sama lain sehingga pembelajaran menjadi seimbang antara pengetahuan, religi, afektif dan tindakan.

Berdasarkan pengamatan Pendidikan moral menekankan pada keteladanan, penciptaan, lingkungan, dan pembiasaan; melalui berbagai tugas keilmuan dan legiatan kondusif. Berbagai tindakan moral yang berhubungan dengan penglihatan, pendengaran, rasa dan tingkah laku yang ada dalam sekolah dapat membentuk karakter siswa. Keteladanan dan faktor pembiasaan perlu ditekankan dalam memberikan pembelajaran langsung kepada siswa tentang moralitas.

\section{Pembahasan}

Implementasi peningkatan moral secara terintegritas merupakan hal yang penting, mengingat penyadaran moralitas tidak dapat berdiri sendiri. Seluruh stakeholder sekolah harus bersama-sama menciptakan sistem yang dapat memacu siswa melakukan tindakan moral yang dilandasi oleh moral reasioning. Implementasi integratif dalam peningkatan moral tidak bersifat dikotomi, objek kajian merupakan satu kesatuan sehingga pengaruh antara objek kajian dengan lingkungannya menjadi satu kesatuan. Model pendidikan moral lebih efektif dengan menggunakan model terintegrasi karena semua pihak mempunyai kontribusi terhadap pembentukan moral. Pemilihan model terintegrasi dinilai lebih baik daripada model pendidikan moral yang berdiri sendiri, karena hal ini akan menyebabkan siswa tidak pembelajaran lainnya tidak menekankan pada ranahranah moral. Fenomena degradasi moral yang terjadi pada siswa sebenarnya bukan saja sepenuhnya faktor kesalahan pendidikan.

Moralitas siswa terjadi karena akumulasi dari tiga pusat pendidikan yaitu faktor keluarga, lingkungan dan sekolah. 
Sekolah yang merupakan salah satu kawasan pendidikan moral perlu didukung oleh pendidikan dalam keluarga dan lingkungan untuk menguatkan moralitas siswa yang dididik di sekolah.

Kurikulum sistem pendidikan yang telah memberikan penekanan yang kuat terhadap nilai-nilaiai moral, perlu adanya dukungan berbagai stakeholder di lingkungan sekolah untuk menciptakan suasana budaya sekolah yang menumbuhkembangkan karakteristik siswa. Dalam kurikulum 2013 memberikan fokus output pendidikan ke dalam penguatan empat ranah utama yaitu ranah ranah spiritual, ranah afektif, ranah kognitif serta ranah psikomotor.

Degradasi moral yang disinyalir mulai muncul di tataran pendidikan perlu diantisipasi dengan berbagai strategi. Berbagai kebijakan yang telah ditetapkan oleh pemerintah tentang arah pendidikan perlu direaktualisasi kembali agar implementasi sistem pendidikan dapat mengantisipasi peningkatan penurunan moralitas tersebut. Penyegaran kembali penerapan sistem pendidikan dapat ditempuh secara terintegratif.

Implementasi integratif tersebut dimaknai sebagai pelaksanaan secara menyeluruh. Komitmen seluruh stakeholder pendidikan diperlukan dalam rangka reaktualisasi penerapan sistem pendidikan yang mengacu pada peningkatan moral tersebut. Komponenkomponen tersebut antara lain kurikulum, rencana pembelajaran, proses pembelajaran mekanisme penilaian, kualitas hubungan, pengelolaan pembelajaran pengelolaan sekolah, pelaksanaan pengembangan diri peserta didik, pemberdayaan sarana prasarana, pembiyaan serta etos kerja seluruh warga dan lingkungan sekolah. Berbagai strategi yang dapat ditempuh antara lain:
1. Penguatan sistem dalam budaya sekolah.

Budaya sekolah merupakan bagian dari pembentukan sikap moral, yaitu dengan memberikan acuan hasil akhir pembentukan moral yang dapat dijadikan slogan untuk sekolah. Salah satu contoh slogan tersebut adalah "KARAKTER" yang artinya Keimanan, Amanah, Rasa nasionalisme, Akademi, Kemanusiaan, Terbuka, Empati dan Rukun. Slogan-slogan ini menjadikan arah kebijakan tujuan pembentukan moral. Slogan-slogan tersebut kemudian disosialisasikan kepada semua siswa untuk dapat diimplementasikan dalam kehidupan sekolah. Membangun sistem yang mendukung tersenggaranya kehidupan sekolah yang berkarakter dengan memberikan berbagai fasilitas yang dapat meningkatkan karakter siswa.

Pemasangan banner di berbagai sudut sekolah merupakan juga salah satu upaya untuk mengingatkan kembali nilainilai budaya yang mengacu pada peningkatan moralitas. Banner yang berbunyi "Malu Rasanya Apabila Mencontek di Kelas" merupakan salah satu strategi untuk mengingatkan siswa untuk mempunyai budaya malu mencontek. Senyum, sapa, dan salam juga merupakan strategi kebijakan sekolah yang perlu diciptakan. Tradisi yang sudah dijalankan oleh guru yaitu memberi salam kepada siswa di depan pintu gerbang merupakan salah satu manivestasi dari upaya meningkatkan interaksi antaranggota sekolah.

2. Penguatan ESQ, EQ dan pembiasaan.

Strategi ini muncul berdasarkan kenyataan bahwa seseorang yang tahu tentang moral, belum tentu melaksanaan tindakan moral yang berdasarkan moral reasioning. Seseorang yang tahu bahwa korupsi itu merugikan negara dan membuat rakyat sengsara, ada saja yang melakukan tindakan korupsi. Seseorang yang tahu tentang korupsi yang melakukan 
tindakan korupsi karena tidak mempunyai dasar yang kuat yaitu Emotional Spiritual Quotien (ESQ), Emotional Quotien (EQ) dan Pembiasaan. Selama siswa tidak memiliki dasar-dasar yang kuat tentang ESQ, EQ dan faktor pembiasaan maka di masa mendatang bisa terjadi siswa tersebut melanggar moral yang telah diketahuinya.

Pembiasaan dapat dilakukan dengan membangun warung kejujuran. Melalui warung kejujuran siswa belajar berlaku jujur dengan membeli dan membayar sendiri tanpa diketahui oleh siapapun. Perilaku ini sebenarnya lebih menekankan pada aspek pembiasaan. Diharapkan dengan seringnya melaksanakan perilaku moral yang didasari oleh kesadaran tentang alasan melakukan tindakan moral, akan memberikan dasar-dasar yang kuat terhadap perilaku moral dalam kehidupannya. Penguatan ESQ bisa dilakukan dengan menyediakan fasilitasfasilitas beribadah yang dapat mewadahi berbagai agama untuk dapat beribadah dengan waktu yang telah disediakan. Kebersamaan dan saling mengingatkan antarteman juga menjadi strategi untuk bersama-sama menjalankan penguatan spiritual.

Penguatan EQ dilakukan dengan cara meningkatkan rasa empati terhadap seluruh komponen sekolah dengan memberikan tauladan yang baik. Tauladan merupakan salah satu media yang tepat untuk memberikan contoh secara nyata kepada setiap siswa. Keteladan dapat menjadi strategi imitasi siswa untuk dapat mencontoh berbagai tindakan moral agar ditiru oleh siswa. Penguatan yang terakhir adalah pembiasaan. Sesuatu yang terbiasa dilakukan maka akan menjadikan perilaku moral. Perilaku moral tersebut tentu saja perlu didasari oleh kesadaran untuk melakukan tindakan tersebut. Perilaku moral yang tidak dilandasi oleh moral reasioning tidak dapat dikatakan peningkatan moral.
3. Perubahan indoktrinasi kepada pembelajaran tidak langsung

Konsep pembelajaran di Indonesia ternyata didominasi oleh pembelajaran langsung, sehingga proses indoktrinasi menjadi salah satu ciri pembelajaran moral. Indoktrinasi hanya akan menghasilkan dua kemungkinan. Pertama nilai-nilai yang diindoktrinasikan diserap bahkan dihafal luar kepala, tetapi tidak terinternalisasi. Kedua, nilai-nilai tersebut diterapkan dalam kehidupan, tetapi karena adanya pengawasan bukan karena kesadaran sendiri. Indoktrinasi dalam proses pembelajaran akan menghasilkan siswa yang mengerti akan moral, tetapi tidak dapat mengimplementasikan dalam kehidupan. Hal inilah yang memberikan dasar asumsi mengapa siswa kadang melakukan pelanggaran moral, padahal peserta didik memahami akan arti moral. Pemahaman akan moral hanya sebatas pada teoritis dan normatif saja, sehingga kadang terjadi perbedaan perilaku dari siswa dalam penerapannya.

Dalam proses pembelajaran, agar tidak terjerumus pada indoktrinasi perlu mendorong peserta didik untuk menemukan alasan-alasan yang mendasari keputusan moral. Hal ini diperlukan agar peserta didik dapat benar-benar memahami keputusan moral yang diambilnya, dapat mengidentifikasi alasan yang harus diterima dan alasan tidak baik untuk ditolak. Siswa perlu dapat memutuskan perubahan yang perlu dilakukan. Alasan yang baik adalah yang memberikan kontribusi dalam mengatasi situasi yang problematik.

Esensi pendidikan guna perbaikan moral tidak dibangun dengan memberikan pengetahuan moral saja. Pengetahuan moral tidak akan mengubah moral, apabila peserta didik tidak memiliki kesadaran moral. Siswa yang mempunyai pengetahuan moral belum tentu akan melaksanakan tindakan moral. Materi- 
materi yang diberikan kepada siswa dalam bentuk pengetahuan perlu ditingkatkan menjadi suatu tindakan moral.

Apabila hal tersebut tidak dilaksanakan, maka siswa hanya memiliki nilai teori yang tinggi, namun tetap melaksanakan tindakan-tindakan yang bertentangan dengan moral walaupun peserta didik tahu tentang moral. Guru perlu memberikan keseimbangan antara rahan spiritual, afektif, kognitif dan psikomotor kepada siswa. Strategi belajar guru perlu diubah dengan pola tidak langsung yaitu memberi target aspek moral yang akan dituju, kemudian memfasilitasi siswa untuk dapat mencapai tujuan tersebut. Contoh dari strategi ini antara lain guru memberikan memulai pembelajaran yang bermuatan afektif seperti kasih sayang, tanggungjawab, empati, yang sesuai dengan materi, kemudian guru mulai memberi materi pembelajaran sambil memberikan aspekaspek afektif dan spiritual sebagai strategi meningkatkan kesadaran moral. Perkembangan zaman mengharuskan guru untuk terus berkembang dan meningkatkan kompetensinya (Nurgiansah \& Pringgowijoyo, 2020). Peningkatan nilainilai moral juga dapat terbangun dari berbagai ekstrakulikuler yang dapat meningkatkan rasa cinta budaya, kedisiplinan, tanggungjawab, kepemimpinan serta berbagai muatan karakter lain yang bersinggungan dengan moralitas. Ekstrakurikuler yang ada di sekolah tetap memprioritaskan nilai-nilai moral yang menjadi tujuan akhir dari pembentukan sikap moral siswa dengan tetap berpaku pada sistem budaya sekolah.

\section{KESIMPULAN}

Kesimpulan yang dapat diambil dari pembahasan masalah reaktualisasi implementasi sistem pendidikan di sekolah dalam mengantisipasi degradasi moral adalah perlunya penyegaran kembali pelaksanaan sistem pendidikan di sekolah dengan membangun komitmen bersama seluruh stakeholder pendidikan untuk melaksanakan berbagai strategi. Strategi yang dapat ditempuh antara lain (1) penguasan sistem dalam budaya sekolah, dengan membangun budaya sekolah yang terfokus pada peningkatan moral, pembuatan slogan yang mengacu pada peningkatan moral, mapun membuat banner; (2) penguatan penguatan ESQ, EQ dan Pembiasaan seperti pemberian waktu yang longgar untuk melaksanakan perlu meningkatkan budaya sekolah yang bebasis nilai-nilai moral seperti membuat slogan, banner, dan warung kejujuran sebagai upaya faktor pembiasaan melakukan tindakan moral, ibadah bersama membangun warung kejujuran, serta (3) perubahan indoktrinasi kepada pembelajaran tidak langsung, dengan berbagai strategi pembelajaran yang mengarah pada pembentukan nilai sikap yang dilandasi oleh moral reasioning. Saran yang menjadi rekomendasi karya ini antara lain untuk siswa perlu meningkatkan nilainilai moral dengan melakukan tindakan moral yang didasari oleh pemahaman alasan melakukan tindakan moral tersebut (moral reasioning). Guru perlu merubah sistem pembelajaran dari indoktrinasi kepada sistem pembelajaran tidak langsung.

\section{DAFTAR PUSTAKA}

Abdulah Munir. 2010. Pendidikan Karakter, Membangun Karakter Anak Sejak dari Rumah. Yogyakarta: Pedagogia.

Asri Budiningsih. 2008. Pembelajaran moral, Berpijak pada Karateristik Siswa dan Budayanya. Jakarta: Rineka Cipta

Bagus Mustakim. 2011. Pendidikan Karakter, Membangun Delapan Karakter Emas Menuju 
Indonesia Bermaetabat. Yogyakarta: Samudra Biru.

Darmiyati Zuchdi. 2010. Humanisasi Pendidikan. Jakarta: Bumi Dharma Aksara.

Kesuma, dkk. 2011. Pendidikan Karakter, Kajian dan Praktik di Sekolah. Bandung: Remaja Rosdakarya.

Furqon Hidayatullah. 2010. Pendidikan Karakter: Membangun Peradaban Bangsa. Surakarta: Yuma Pustaka.

Lexy J Moleong. 2008. Metodologi Penelitian Kualitatif. Bandung: Remaja Rosdakarya.

Masnur Muslich. 2011. Pendidikan Karakter: Menjawab Tantangan Krisis Multidimensional. Jakarta: Bumi Aksara.

Mulyasa. 2013. Pengembangan dan Implementasi Kurikulum 2013. Bandung: Remaja Rosdakarya.

Musaheri. 2007. Pengantar Pendidikan. Yogyakarta: IRCiSoD.

Nur Baity. 2013. Implementasi Pendidikan Moral dalam Proses Pembelajaran di Sekolah.

Nurgiansah, T. H. (2019). Pemutakhiran Kurikulum Pendidikan Kewarganegaraan di Era Revolusi Industri 4.0. Prosiding Seminar Kewarganegaraan Universitas Negeri Medan, 1(1), 95-102.

Nurgiansah, T. H. (2020). Build An Attitude of Nationalism Students At SDN 7 Kadipaten With The Method of Discusion In The Subject PPKn. Jurnal Serunai Pendidikan Pancasila Dan Kewarganegaraan STKIP Budi Daya Binjai, 9(1), 1-11.

Nurgiansah, T. H., \& Al Muchtar, S. (2018). Development of Student Awareness through Student Learning Model Jurisprudential in Citizenship Education. ATLANTIS PRESS, 251(Acec), 670-674. https://doi.org/10.2991/acec-18.2018.150

Nurgiansah, T. H., \& Pringgowijoyo, Y. (2020). Pelatihan Penggunaan Model Pembelajaran Jurisprudensial Pada Guru Di KB TK Surya Marta Yogyakarta. KUAT: Keuangan Umum Dan Akuntansi Terapan. PKNSTAN, 2(1).

Nurgiansah, T. H., \& Widyastuti, T. M. (2020). Membangun Kesadaran Hukum Mahasiswa PPKn UPY Dalam Berlalu Lintas. Civic Edu: Jurnal Pendidikan Kewarganegaraan Universitas Pasundan, 2(2), 97-102. https://doi.org/10.1017/CB09781107415324.004 Redja Mudyahardjo. 2001. Pengantar Pendidikan. Jakarta: Raja Grafindo. Rohmat Mulyana 2004. Mengartikulasikan Pendidikan Nilai. Bandung: Alfa Beta Suharsimi Arikunto,dkk 2012. Penelitian Tindakan Kelas. Jakarta: Bumi Aksara. Sutiyono. 2013 Peranan Sekolah dan Keluarga dalam Membentuk Karakter Siswa. 